\title{
Efeito da densidade de criação e do grupo genético sobre a composição mineral e desenvolvimento de ossos longos de frangos de corte
}

\section{Effect of stocking density and genetic group on mineral composition and development of long bones of broilers}

\author{
Andréia Fróes Galuci Oliveira" ${ }^{1 *}$; Luís Daniel Giusti Bruno²; Elias Nunes Martins ${ }^{3}$; \\ Elis Regina de Moraes Garcia ${ }^{4}$; Ana Carolina Monteiro ${ }^{5}$; \\ Meiby Carneiro de Paula Leite ${ }^{6}$; Paulo César Pozza ${ }^{7}$; Cleiton Pagliare Sangali ${ }^{8}$
}

\section{Resumo}

O objetivo do trabalho foi avaliar a composição mineral, volume, resistência e densidade óptica radiográfica dos ossos longos (úmero, tíbia e fêmur) de frangos de corte de três grupos genéticos e duas densidades de alojamento. O delineamento experimental utilizado foi inteiramente casualizado em um esquema fatorial $3 \times 2$, em parcelas subdivididas, sendo os fatores principais os três grupos genéticos (Isa Label JA57, Ross 308 e Hybro PG) e as duas densidades de alojamento (10 e 16 aves/ $\mathrm{m}^{2}$ ), e as subparcelas as idades de coleta dos ossos (7 semanas), totalizando deste modo seis tratamentos com cinco repetições cada um num total de 30 unidades experimentais. Os resultados deste trabalho apontaram que não houve diferenças significativas para as características avaliadas com exceção da resistência da tíbia para o grupo Isa Label JA57. O volume ósseo apresentou-se crescente com a idade da ave; já a resistência à quebra e densidade óptica radiográfica para a maioria dos tratamentos avaliados decresceram dos 28 aos 35 dias. O teor de minerais dos ossos avaliados para todos os tratamentos mostrou-se crescente nas três primeiras semanas, decrescendo no final do período experimental. $\mathrm{O}$ modelo de desenvolvimento ósseo foi o mesmo para todos os grupos genéticos, apesar da densidade de criação adotada, mostrando que os frangos de corte possuem uma curva padrão de crescimento ósseo, que não é afetada pelo grupo genético ou pela densidade de criação.

Palavras-chave: Desenvolvimento, fêmur, frangos de corte, tíbia, úmero

\footnotetext{
Abstract

The objective of this experiment was to evaluate the mineral composition, volume, bone breaking strenght and optical radiographic density of long bones (humerus, tibia and fêmur) of broiler chickens from three genetic groups and two rearing densities. The experimental design was a splitj-splot where the

${ }^{1}$ Prof $^{\text {as }}$ do Curso de Agronomia, Unidade Universitária de Cassilândia da Universidade Estadual de Mato Grosso do Sul, UEMS, Cassilândia, MS. E-mail: andreiafroes@hotmail.com; anamonteiro@grupointegrado.br

${ }^{2}$ Profs. do Centro de Ciências Agrárias, Universidade Estadual do Oeste do Paraná, UNIOESTE, Marechal Cândido Rondon, PR. E-mail: 1dgbruno@gmail.com; cpsangali@hotmail.com

${ }^{3}$ Prof. do Dept ${ }^{0}$ de Zootecnia, Universidade Estadual de Maringá, UEM, Maringá, PR. E-mail: enmartins@uem.br

${ }^{4}$ Prof ${ }^{a}$ da Universidade Estadual de Mato Grosso do Sul, UEMS, Unidade Universitária de Aquidauana, Aquidauana, MS. E-mail: ermgarcia@hotmail.com

${ }^{5}$ Prof ${ }^{a}$ do Curso de Medicina Veterinária e Agronomia da Faculdade Integrado, Campo Mourão, PR. E-mail: anamonteiro@

${ }^{6}$ Prof $^{\mathrm{a}} \mathrm{Dr}^{\mathrm{a}}$ do Centro de Ciências Agrárias, Ambientais e Biológicas, CCAAB, Universidade Federal do Recôncavo da Bahia, UFRB, Cruz das Almas, BA. E-mail: meiby@ufrb.edu.br

${ }^{7}$ Prof. do Dept ${ }^{\circ}$ de Zootecnia, UEM, Maringá, PR. E-mail: pcpozza@uem.br

${ }^{8}$ Prof. do Centro de Ciências Agrárias, UNIOESTE, Marechal Cândido Rondon, PR. E-mail: cpsangali@hotmail.com

* Autor para correspondência
} grupointegrado.br 
main plots were a combination of three genetic groups (Isa Label JA57, Ross 308 and Hybro PG) and two rearing densities ( 10 and 16 birds $/ \mathrm{m}^{2}$ ) in a factorial arrangement, and age was considered a secondary plot, so there was six treatments with 5 replications per each treatment, totalizing 30 experimental units. The results founded showed that there were no differences in the studied genetic groups when submitted to two rearing densities for all evaluated parameters, with exception for bone breaking strength of tibia from Isa Label JA57. Bone volume increased with broiler age, while bone breaking strength and bone density showed a decreased from 28 to 35 days of age. Bone mineral content for all treatments showed up growing in the first three weeks, decreasing in the end of the experimental period. The pattern of bone development was the same for all genetic groups, despite the rearing density used, showing that broilers had a standard bone growth curve that is not affected by genetic or rearing density.

Key words: Broiler chickens, development, femur, humerus, tibia

\section{Introdução}

Nos últimos anos tem-se optado por criações de frangos de corte em alta densidade com intuito de aumentar a produtividade e a lucratividade do avicultor em um curto espaço de tempo. Para que esta finalidade seja alcançada, é alojado um maior número de aves por área. Isto acarreta em menor crescimento individual das aves, mas por outro lado proporciona a produção de maior quantidade de carne por área útil.

Existem no mercado diversas linhagens de frangos de corte. Apesar dos programas de melhoramento genético conduzidos pelas empresas buscarem os mesmos objetivos - maior rendimento de peito e de coxa, estas linhagens apresentam algumas diferenças genéticas entre si, expressas na velocidade de crescimento, principalmente nas primeiras semanas de vida. Esta alta atividade metabólica inicial tem sido responsabilizada pela ocorrência de diversos problemas metabólicos, tais como a ascite e a síndrome da morte súbita, e também de algumas anomalias ósseas, tais como a discondroplasia tibial (PRAUL et al., 2000).

Além destas diferenças genéticas, outros fatores podem influenciar o desenvolvimento ósseo das aves, tais como: idade, sexo, manejo, nutrição, temperatura (COOK, 2000; EDWARDS JUNIOR, 2000; BRUNO et al., 2000; BIZERAY et al., 2002, BRUNO et al., 2007).

O osso constitui-se de $22 \%$ de matriz óssea orgânica, $9 \%$ de água e 69\% de materiais inorgânicos. A matriz orgânica tem como componente predominante o colágeno $(90 \%)$, que participa no processo de mineralização óssea (ARAÚJO et al., 2006). O osso é composto de regiões que são denominadas epífises, diáfise e uma região intermediária entre a epífise e a diáfise, a metáfise (BARREIRO et al., 2009).

No processo de avaliação do desenvolvimento ósseo são utilizados parâmetros físicos e químicos para estimar o grau de maturidade do tecido. Dentre os parâmetros químicos, o teor de matéria mineral da tíbia tem sido o principal método pelo qual a mineralização óssea tem sido avaliada (HALL et al., 2003). Onyango et al. (2003) concluíram que a densitometria óssea poderia ser usada para estimar a porcentagem de matéria mineral na tíbia de frangos de corte. A densitometria óptica radiográfica é uma das metodologias utilizadas para inferir o conteúdo mineral dos ossos, através de suas imagens radiográficas (LOUZADA et al., 1998). Apesar das técnicas de avaliação quantitativa e qualitativa do estado de mineralização óssea estarem avançando de forma relativamente acentuada, seus graus de complexidade e de custo impedem, até certo ponto, sua utilização de forma rotineira.

Diante do exposto, foi desenvolvido este trabalho com o objetivo de avaliar o teor de minerais, volume, resistência à quebra e densidade óptica radiográfica dos ossos longos de diferentes grupos genéticos criados em duas densidades populacionais.

\section{Material e Métodos}

O experimento foi conduzido no aviário da 
fazenda experimental de Iguatemi, da Universidade Estadual de Maringá, com duração de 42 dias. Foram utilizados três grupos genéticos de frangos de corte: Hybro PG, Isa Label JA57 e Ross 308, adquiridos de um incubatório comercial (matrizes com 42 semanas de idade), totalizando 2160 pintainhos machos de um dia de idade, sendo 720 para cada grupo genético, e duas densidades de criação: 10 e 16 aves $/ \mathrm{m}^{2}$.

As aves receberam três rações durante o período experimental, formuladas de acordo com a idade das aves: inicial (1-21 dias), crescimento (22-35 dias) e final (36-42 dias), seguindo as recomendações nutricionais do NRC (1994) e a composição química dos alimentos de Rostagno et al. (2000).

Durante todo o período experimental a ração e água foram fornecidas ad libitum para as aves. A composição percentual das rações, bem como os níveis calculados, está apresentada na Tabela 1.

Tabela 1. Composição percentual e calculada das dietas experimentais dos frangos de corte nas fases inicial (1-21 dias), de crescimento (22-35 dias) e final (36-42 dias).

\begin{tabular}{lccc}
\hline & \multicolumn{3}{c}{ Fases de criação } \\
\cline { 2 - 4 } Ingredientes (\%) & Inicial & Crescimento & Final \\
\hline Milho moído & 53,23 & 54,54 & 62,00 \\
Farelo de soja & 39,94 & 37,53 & 30,49 \\
Óleo degomado & 2,91 & 4,71 & 4,70 \\
Fosfato bicálcico & 1,61 & 1,10 & 0,90 \\
Calcáreo & 1,40 & 1,43 & 1,33 \\
Sal comum & 0,45 & 0,33 & 0,25 \\
Sup. Min. Vit. ${ }^{1}$ & 0,15 & 0,20 & 0,20 \\
DL-Metionina & 0,21 & 0,06 & 0,03 \\
BHT & 0,10 & 0,10 & 0,10 \\
\hline Níveis nutricionais e energéticos & & Valores calculados & 3.200 \\
\hline Energia Metabolizavel (kcal/kg) & 2.950 & 3.100 & 18,50 \\
Proteína Bruta (\%) & 22,00 & 21,00 & 0,80 \\
Cálcio (\%) & 1,00 & 0,90 & 0,30 \\
Fósforo disponível (\%) & 0,45 & 0,35 & 0,60 \\
Metionina + cistina (\%) & 0,90 & 0,72 & 0,32 \\
Metionina (\%) & 0,53 & 0,38 & 0,85 \\
Lisina (\%) & 1,24 & 1,00 & 172,9 \\
\hline Relação EM:PB & 134,1 & 147,6 & \\
\hline
\end{tabular}

${ }^{1}$ Premix vitamínico Multi Frango e Multi Mix e premix mineral Multi Mix Nucleopar S.A.

Fonte: Elaboração dos autores.

Os tratamentos foram: T1 - Isa Label JA57 com densidade de criação de 10 aves $/ \mathrm{m}^{2} ; \mathrm{T} 2$ - Isa Label JA57 com densidade de criação de 16 aves $/ \mathrm{m}^{2}$; T3 Ross 308 com densidade de criação de 10 aves $/ \mathrm{m}^{2}$; T4 - Ross 308 com densidade de criação de 16 aves/ m²; T5 - Hybro PG com densidade de criação de 10 aves/m²; T6 - Hybro PG com densidade de criação de 16 aves $/ \mathrm{m}^{2}$.
Para avaliação do volume, resistência, densidade óptica radiográfica e composição mineral dos ossos foram sacrificadas aleatoriamente duas aves por repetição nos dias $1,7,14,21,28,35$ e 42 dias de idade para a coleta dos ossos longos (úmero, tíbia e fêmur), dos membros superiores e inferiores tanto do lado esquerdo como do lado direito das aves. Após a coleta os ossos foram descarnados e congelados. 
Posteriormente foram colocados em água fervente por aproximadamente 10 segundos e mergulhados em éter de petróleo por um período de 24 horas para serem desengordurados e então secos em estufa de ventilação forçada a $40 \mathrm{C}^{\circ}$ por 24 horas.

O volume ósseo foi determinado por meio do método de deslocamento de água. Foi utilizada uma balança analítica de precisão $(0,0001 \mathrm{~g})$, na qual foi colocado um recipiente com água. Após o conhecimento do peso da água, foi introduzido no recipiente o osso e, pela diferença de peso obtida, calculou-se o volume ósseo.

O ensaio para a determinação da densidade óptica radiográfica foi realizado na Clínica de Odontologia do Hospital Universitário de Maringá. Em uma primeira etapa as peças ósseas foram radiografadas. Para isto as mesmas foram colocadas sobre o filme (marca Kodak Intra oral E-Speed Film, size2, tipo periapical), todas na mesma posição. Após o preparo as peças foram radiografadas utilizando-se um aparelho de raios-x odontológico Dabi Atlante modelo Spectro 70X, Classe I- Tipo B-Comum, calibrado com distância foco-filme de $25 \mathrm{~cm}$, ajustado para $70 \mathrm{kVp}, 15 \mathrm{mAs}$ e tempo de exposição de 0,3 segundos. Esses valores de tensão, corrente e tempo de exposição foram considerados ideais após análises prévias. Após a obtenção das radiografias as mesmas foram processadas em uma reveladora A/T2000 XR Air Techniques, utilizandose um tempo de processamento de quatro minutos. Sequencialmente as radiografias foram digitalizadas utilizando-se um scanner com a resolução de 600 DPI ("Dots Per Inch" = pontos por polegada), 50\% de brilho, $50 \%$ de contraste, $\mathrm{W}-1,58 ; \mathrm{H}-1,84$; X0,00 e $\mathrm{Y}-0,05$ e gravadas em arquivos com extensão JPG progressivo. A terceira etapa constituiu-se na leitura das radiografias através do software "Adobe Photoshop 7.0". A determinação da densidade óssea foi realizada em uma área específica, a mais central possível, por ser a mesma área que no ensaio de resistência receberia a força necessária à quebra.

A análise de resistência óssea foi realizada no
Laboratório de Materiais de Construção e Mecânica do Solo pertencente ao Centro de Tecnologia da UEM, sendo os valores expressos em kilograma força (Kgf). As peças ósseas foram posicionadas em apoios da região das epífises e ficaram sem apoio na região central. A posição escolhida foi a anteroposterior para evitar que ossos se deslocassem no momento da quebra. A força necessária para a ruptura do osso foi aplicada na região central, sempre no mesmo ponto em todos os ossos. Os valores foram expressos em quilograma força (kgf).

Após o ensaio para a determinação da resistência óssea, os ossos foram preparados para a determinação do teor de matéria mineral, sendo calcinados em mufla a $600{ }^{\circ} \mathrm{C}$ também por 24 horas.

O delineamento experimental utilizado foi inteiramente casualizado em um esquema fatorial $3 \times 2$ com parcelas subdivididas, sendo os fatores principais os três grupos genéticos (Isa Label JA57, Ross 308 e Hybro PG) e as duas densidades de criação (10 e 16 aves $/ \mathrm{m}^{2}$ ) e as subparcelas as idades de coleta dos ossos. Deste modo foram utilizados seis tratamentos com cinco repetições cada um, com um total de 30 unidades experimentais.

A análise estatística dos dados referentes ao desenvolvimento ósseo foi feita pelo método de modelos lineares generalizados (NELDER; WEDDERBURN, 1972), admitindo-se distribuição gama e função de ligação recíproca.

\section{Resultados e Discussão}

Não houve diferenças significativas para o volume ósseo dos frangos dos três grupos genéticos criados nas duas densidades populacionais (Figura 1). O padrão da curva de desenvolvimento do volume ósseo foi semelhante para os três grupos genéticos, com as aves dos grupos Ross 308 e Hybro PG apresentando uma maior velocidade de desenvolvimento no volume ósseo quando comparadas com o do grupo Isa Label JA57. 
Figura 1. Volume dos ossos longos de frangos de corte de três grupos genéticos criados em duas densidades populacionais.

\section{Úmero}

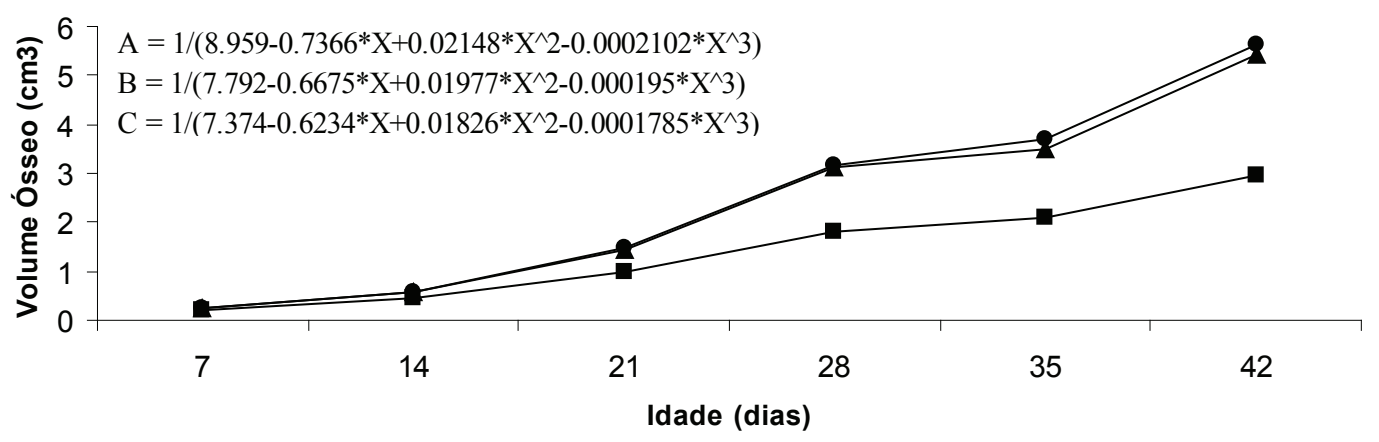

Isa Label x 10 e 16 aves/m2 (A) $\neg$ Ross x 10 e 16 aves/m2 (B) $\bullet-$ Hybro x 10 e 16 aves/m2 (C)

Tíbia

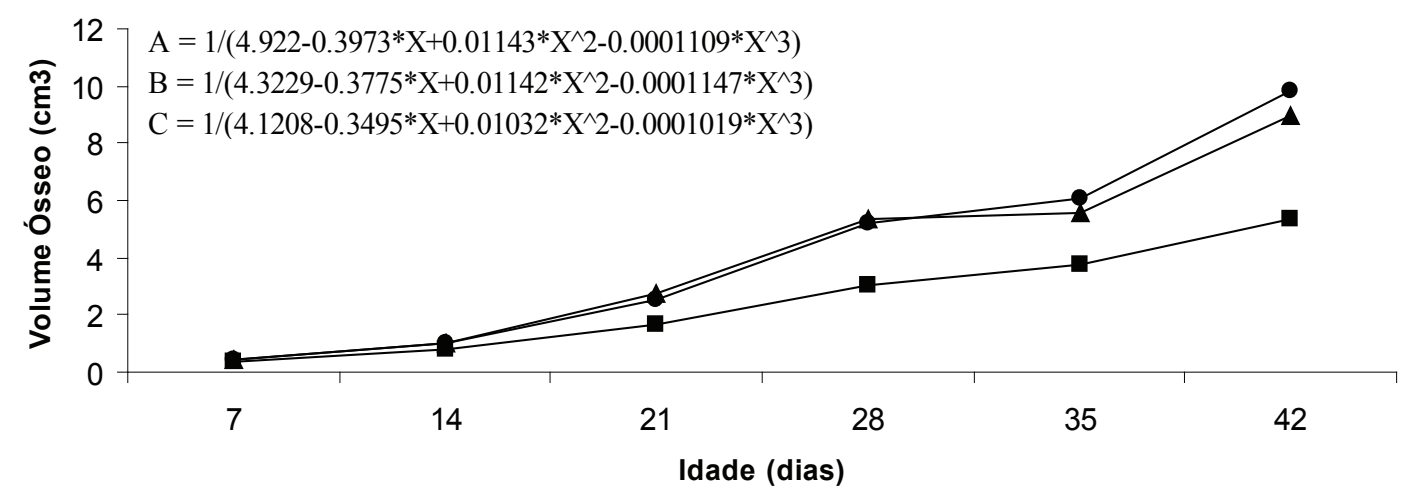

Isa Label x 10 e 16 aves/m2 (A) $\neg$ Ross x 10 e 16 aves/m2 (B) $\rightarrow \bullet$ Hybro x 10 e 16 aves/m2 (C)

Fêmur

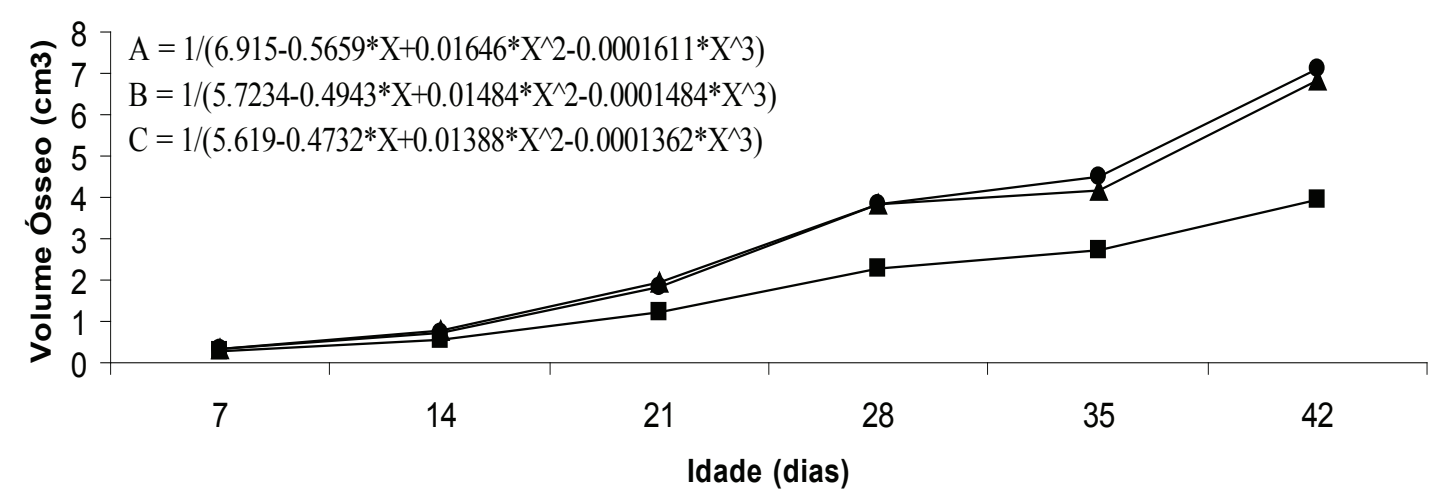

Isa Label x 10 e 16 aves/m2 (A)

$\leftarrow$ Ross $\times 10$ e 16 aves/m2 (B)

Hybro x 10 e 16 aves/m2 (C)

Fonte: Elaboração dos autores. 
Esse efeito pode estar relacionado com as diferenças na intensidade dos programas de melhoramento genético aos quais as aves dos respectivos grupos genéticos foram submetidas: os programas foram muito mais intensos nas aves dos grupos Ross 308 e Hybro PG e menos contundentes nas aves do grupo Isa Label JA57. Os valores de volume ósseo mostraram-se crescentes até os 28 dias de idade, quando apresentaram certa estabilidade em relação aos valores obtidos para 35 dias, voltando a crescer até os 42 dias de idade.

Com relação à resistência à quebra dos ossos longos (Figura 2), foi encontrada diferença para a resistência da tíbia para a linhagem Isa Label JA57 criada na densidade de 10 aves $/ \mathrm{m}^{2}$ em comparação com as aves de mesmo grupo genético criadas na densidade de 16 aves $/ \mathrm{m}^{2}$. Os ossos longos das aves pertencentes aos grupos Hybro PG e Ross 308 apresentaram sempre uma maior resistência à quebra do que os ossos das aves pertencentes ao grupo Isa Label JA57. A resistência à quebra mostrou-se crescente, atingindo seu pico aos 42 dias de idade, indicando que os ossos ainda encontramse em fase de formação nesta idade. $O$ fato de ter havido uma diferença para as aves do grupo genético Isa Label JA57 criados nas duas diferentes densidades populacionais implica teoricamente em uma possível diferença na formação do tecido ósseo decorrente do espaço disponível para movimentação das aves. As aves criadas em menor densidade populacional apresentaram ossos menos resistentes. A explicação para este fato não nos é clara, pois teoricamente uma ave que realiza maior atividade física teria um osso mais resistente, e a maior atividade física seria proporcionada pelo maior espaço físico para movimentação das aves dentro do box experimental. A diferença estatística encontrada na resistência à quebra da tíbia no grupo genético Isa Label JA57, nas idades de 14 e 21 dias, não é facilmente explicada, pois nos demais ossos longos essa diferença não foi observada. Pode ser especulado que esse efeito tenha ocorrido em função de características outras que não as genéticas, como por exemplo, nutricional, ambiental, dentre outras. Esse efeito desapareceu após 28 dias de idade das aves.

A densidade óptica radiográfica dos ossos longos também seguiu o mesmo padrão de desenvolvimento apresentado para os outros parâmetros, sendo as linhagens Hybro PG e Ross 308 as que apresentaram ossos com maior densidade do que a linhagen Isa Label JA57 (Figura 3). Não foram encontradas diferenças entre as duas densidades de alojamento. Tíbia e fêmur apresentaram maiores valores de densidade do que o úmero, podendo este fato ser interpretado em função da exigência funcional dos ossos longos (manutenção da postura animal) da perna os quais têm seu desenvolvimento mais acelerado em relação ao osso da asa. Os dados da Figura 3 mostram que a densidade óssea é crescente até 21 dias de idade, sendo que após este período a mesma não tem variações tão marcantes em função da idade. Estes dados quando analisados com os da Figura 2 (resistência óssea à quebra) revelam que até 21 dias de idade parece ter uma correlação positiva entre densidade e resistência. Knott e Bailey (1998) estudando essa relação (densidade $\mathrm{x}$ resistência) sugeriu que esse efeito pode estar associado com a redução na síntese ou organização do colágeno.

Dos 28 aos 35 dias de idade o comportamento das curvas de resistência e densidade dos três ossos para os três grupos genéticos decresceu. Bruno et al. (2007) encontraram correlação positiva nos quais a resistência óssea aumentou de acordo com a idade da ave para os três ossos, assim como ocorreu neste experimento. 
Figura 2. Resistência dos ossos longos de frangos de corte de três grupos genéticos criados em duas densidades populacionais.

\section{Úmero}

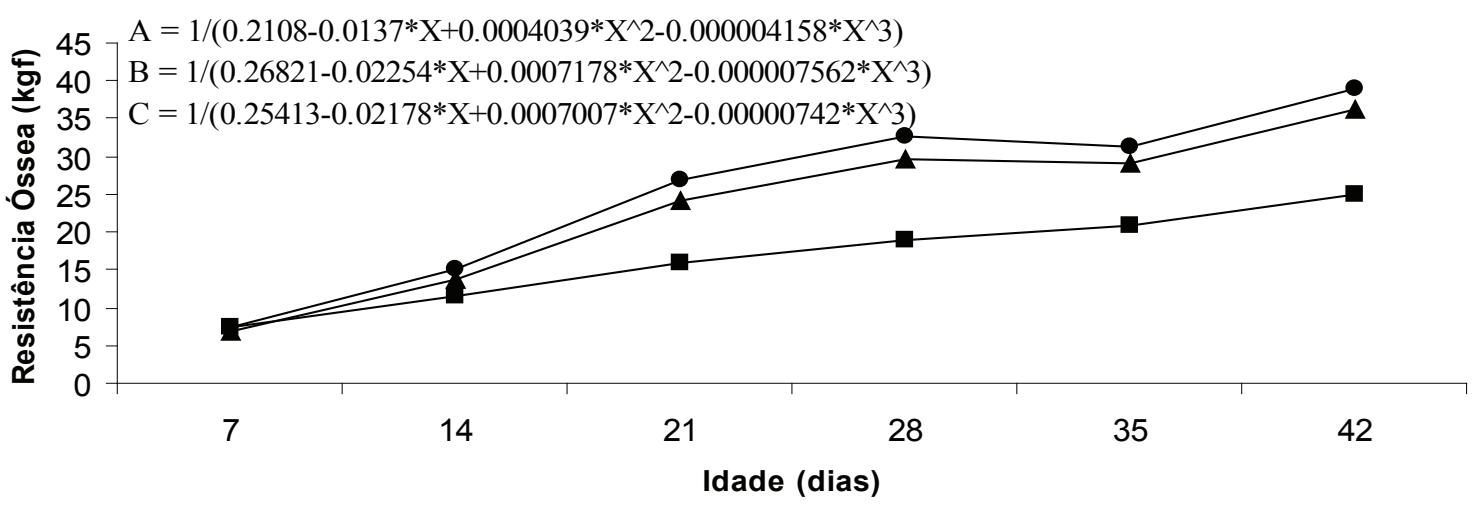

\section{Isa Label x 10 e 16 aves/m2 (A) $\neg$ Ross x 10 e 16 aves/m2 (B) $\bullet-$ Hybro x 10 e 16 aves/m2 (C)}

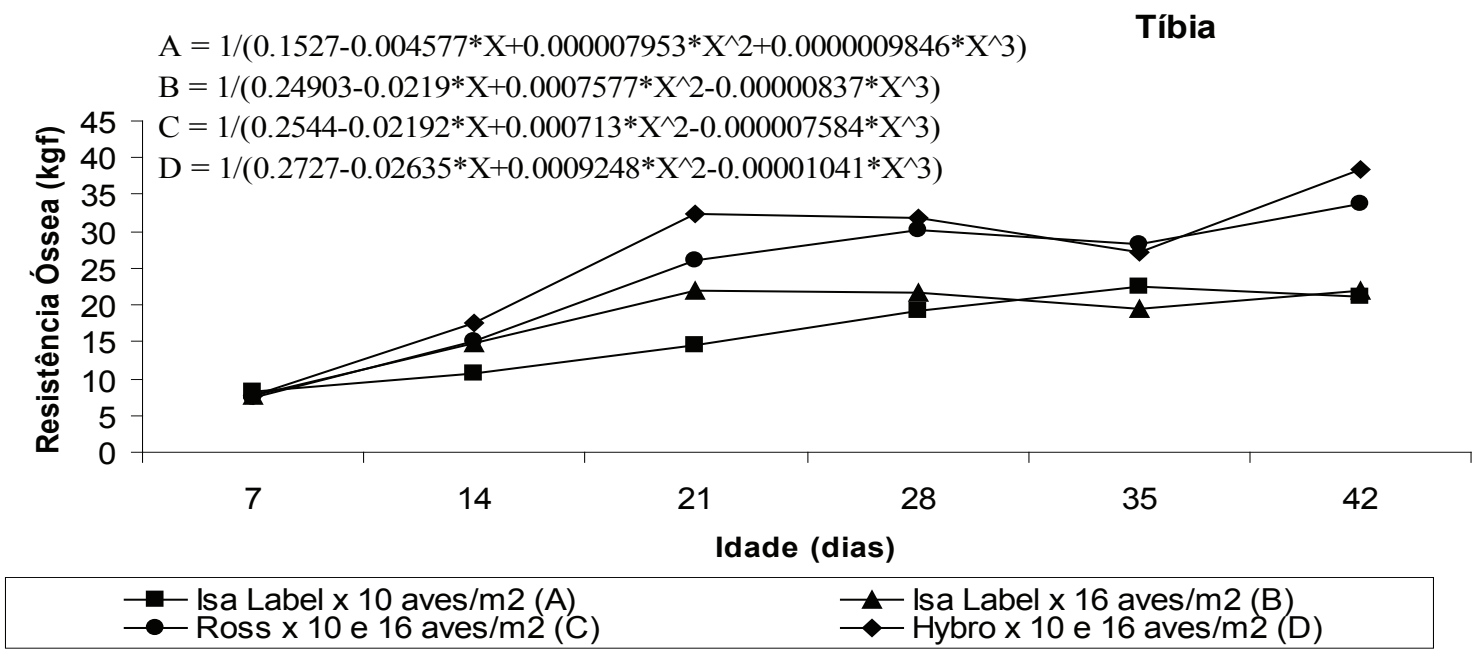

Fêmur

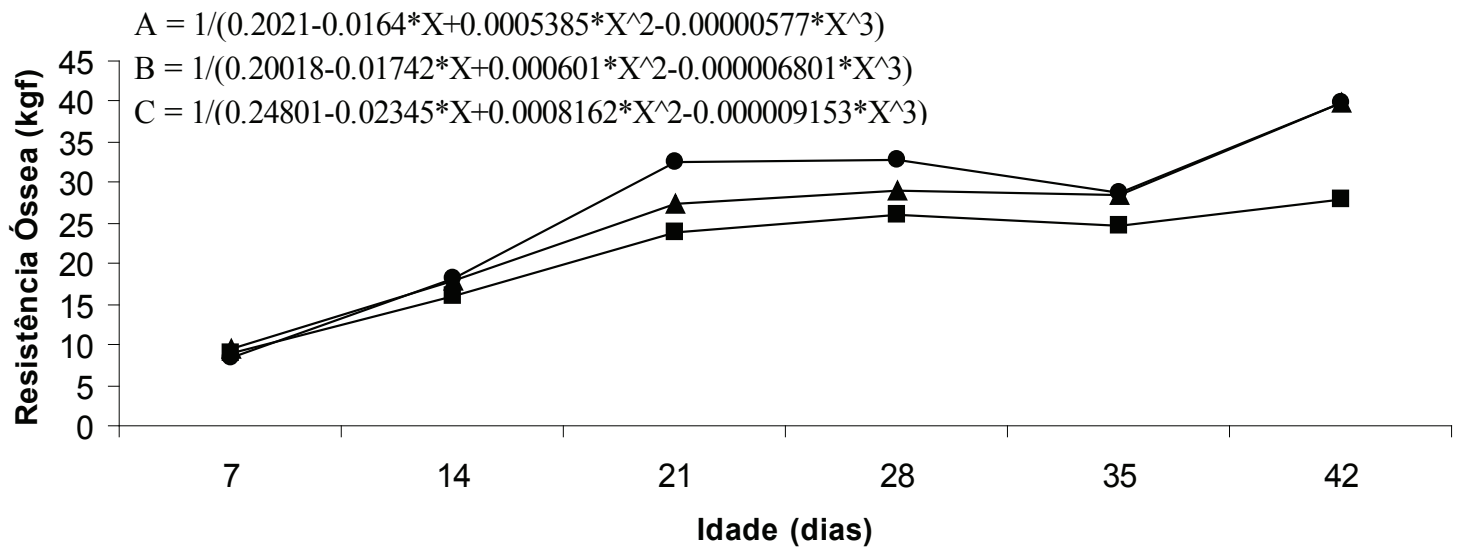

Isa Label x 10 e 16 aves/m2 (A) $\neg$ Ross x 10 e 16 aves/m2 (B) $\bullet-$ Hybro x 10 e 16 aves/m2 (C)

Fonte: Elaboração dos autores. 
Figura 3. Densidade óptica radiográfica dos ossos longos de frangos de corte de três grupos genéticos criados em duas densidades populacionais.

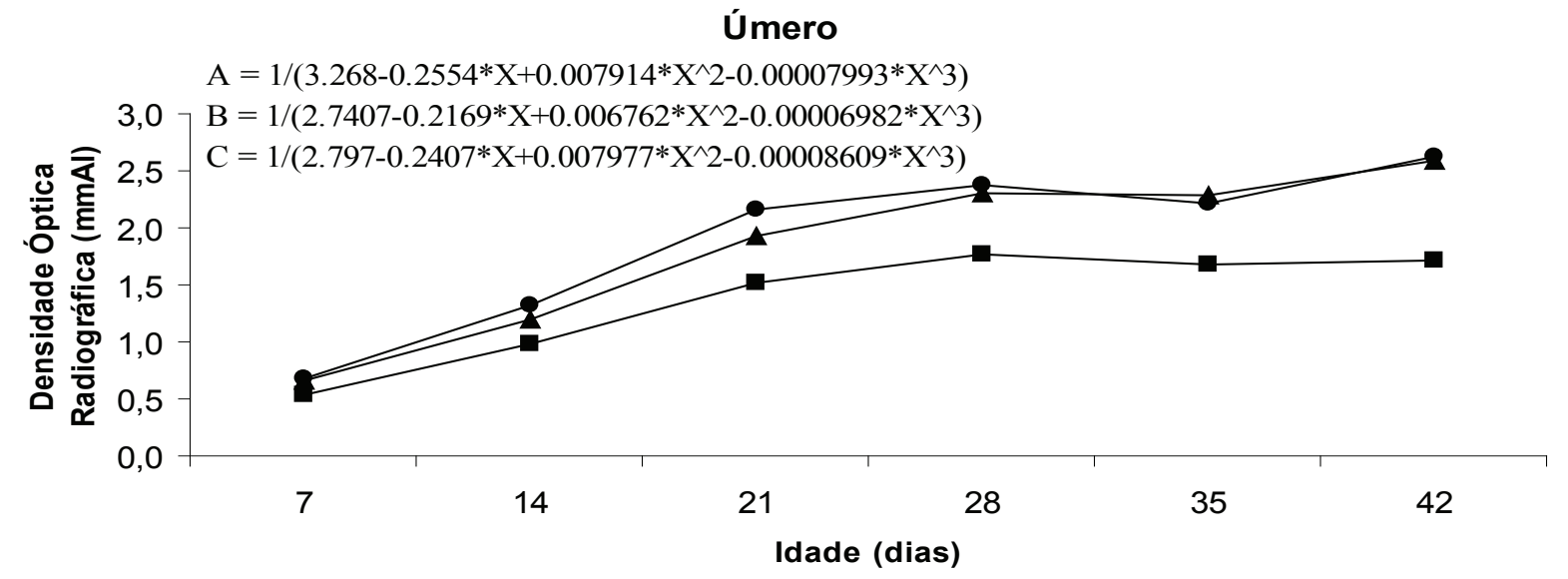

Isa Label x 10 e 16 aves/m2 (A) —-Ross x 10 e 16 aves/m2 (B) $\bullet-$ Hybro x 10 e 16 aves/m2 (C)

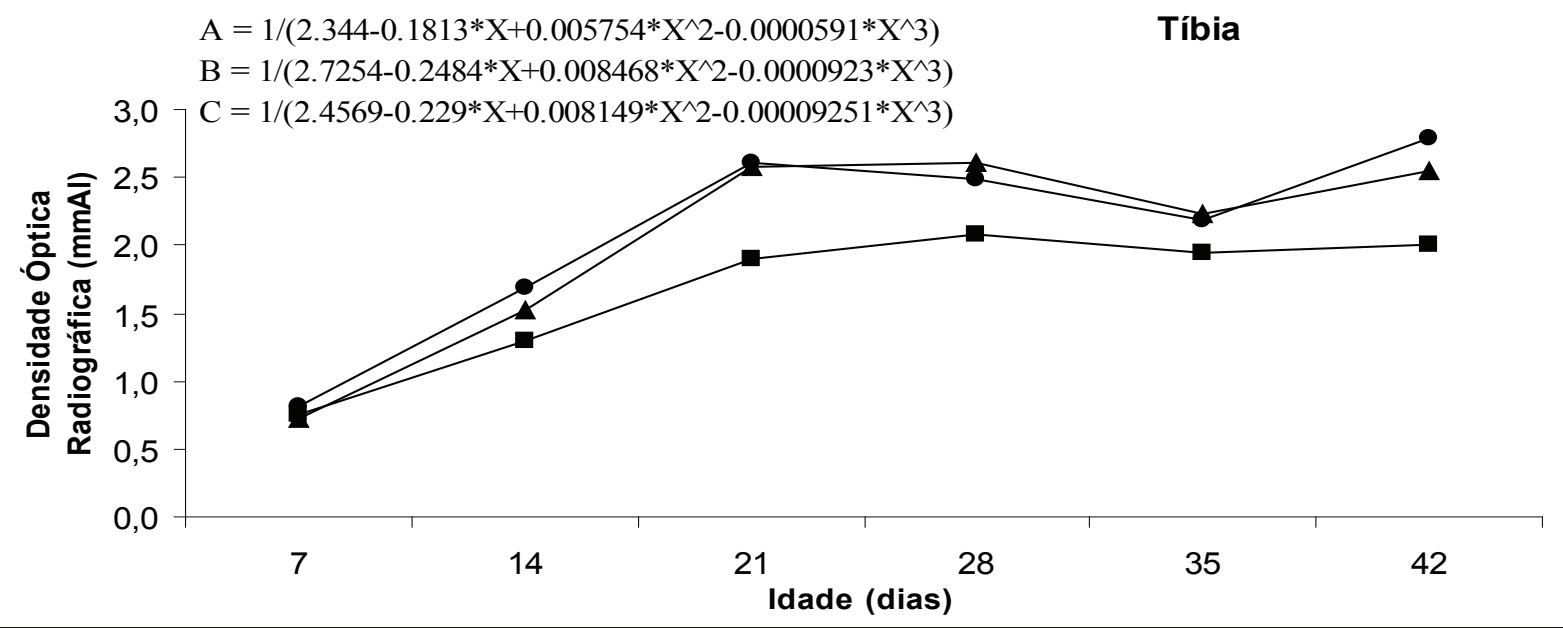

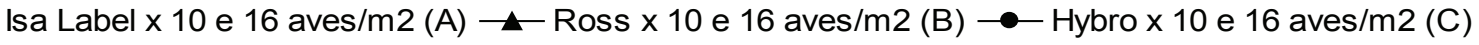

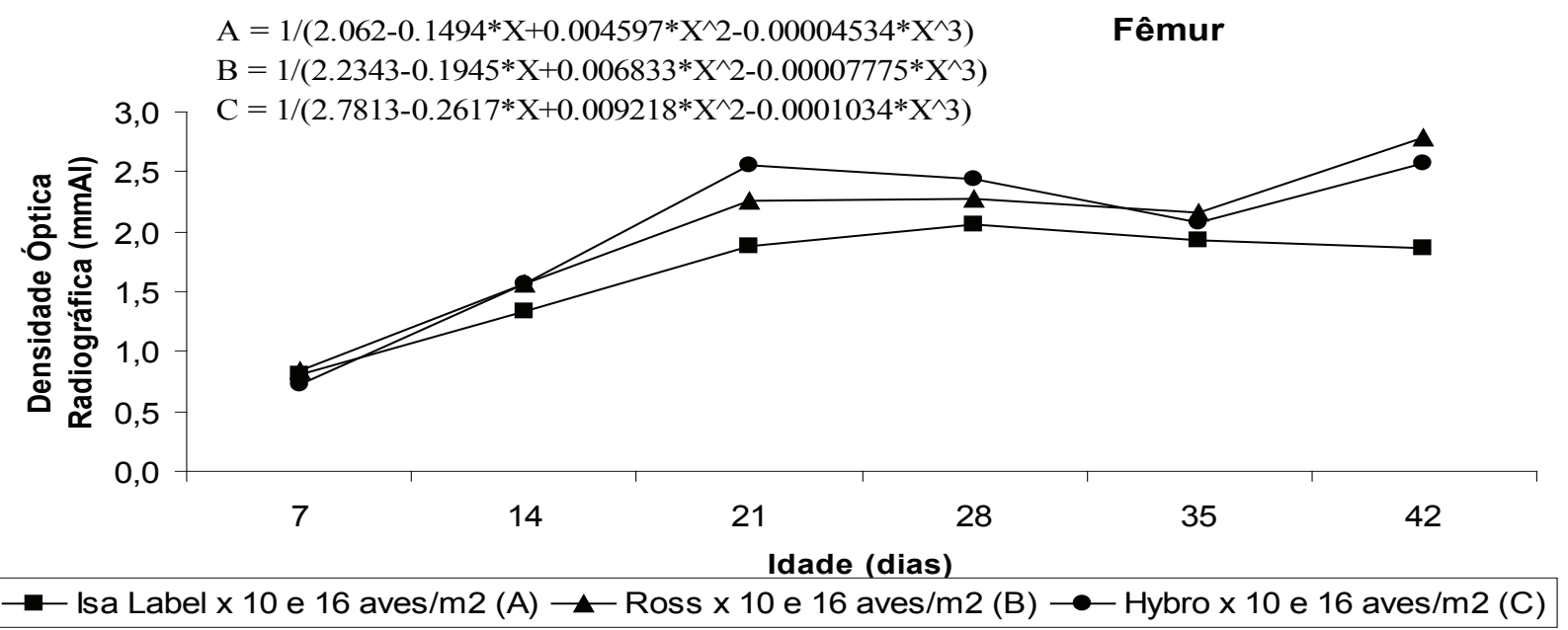

Fonte: Elaboração dos autores. 
A curva calculada para o teor de matéria mineral apresenta um padrão inverso quando comparada com as demais variáveis (Figura 4). Até os 21 dias o teor de matéria mineral é crescente nos ossos, decaindo a partir dessa idade. Mesmo com um menor teor de matéria mineral a resistência e a densidade da tíbia para todos os tratamentos não foram afetados na última semana, pois a densidade e resistência do tecido ósseo não estão relacionados somente com a parte inorgânica (teor de matéria mineral), mas também com a parte orgânica (estrutura de colágenos). Fato confirmado por Rath, Balong e Huff (1999) onde afirmam que a resistência óssea não está condicionada somente com o nível de minerais do osso, mas também com a estrutura orgânica do mesmo. Estes autores explicam que o osso é um tecido complexo composto pelas matrizes orgânica e inorgânica que oferecem suporte e resistência mecânica. A matriz inorgânica, principalmente hidroxiapatita, fornece a resistência à compressão e a matriz orgânica, composta predominantemente por colágeno, provém a resistência à tensão e serve de suporte para a incorporação da matriz orgânica.

A idade da ave mostrou, conforme dito anteriormente, influência no teor de matéria mineral dos ossos longos. Os resultados mostram um aumento na deposição de minerais nas primeiras semanas, resultados estes que corroboram os de Bruno et al. (2007).

Os dados obtidos para as características ósseas para os 3 grupos genéticos, criados nas duas densidades populacionais, evidencia um modelo de desenvolvimento ósseo bem determinado, ou seja, maior desenvolvimento nas três primeiras semanas de vida, em especial os ossos envolvidos na manutenção da postura animal (fêmur e tíbia), com desaceleração a partir da terceira semana, quando, provavelmente, ocorre uma síntese e reorganização do colágeno.

Apesar das diferenças observadas entre os grupos genéticos e as densidades populacionais, o sistema ósseo mostrou, por meio das figuras obtidas, um padrão de desenvolvimento muito bem definido com um forte desenvolvimento inicial (três semanas), leve desaceleração no desenvolvimento seguida por uma retomada no mesmo.

Ao avaliarem-se os dados obtidos de maneira conjunta, verificou-se que existe uma coerência para o comportamento do volume, resistência e densidade óptica radiográfica. Chama a atenção o comportamento da deposição de matéria mineral no tecido ósseo, que tem seu auge ao redor dos 28 dias de idade, decaindo em seguida, levando-nos a crer que a partir desta fase é mais intensa a atividade de deposição e construção de matéria orgânica dentro do osso em relação à matéria mineral nos ossos longos.

De acordo com Sorensen, Su e Kestin (2000), altas densidades de alojamento podem afetar o bem estar das aves pela exarcebação de condições dolorosas, como a fraqueza de pernas. Os autores sugerem ainda que, frangos de corte não sejam criados em altas densidades populacionais para que ocorra uma redução na anomalia óssea conhecida como fraqueza das pernas. Os resultados mostram que as densidades de alojamento testadas não alteraram o padrão de desenvolvimento dos ossos longos das aves. 
Figura 4. Matéria mineral dos ossos longos de frangos de corte de três grupos genéticos criados em duas densidades populacionais.

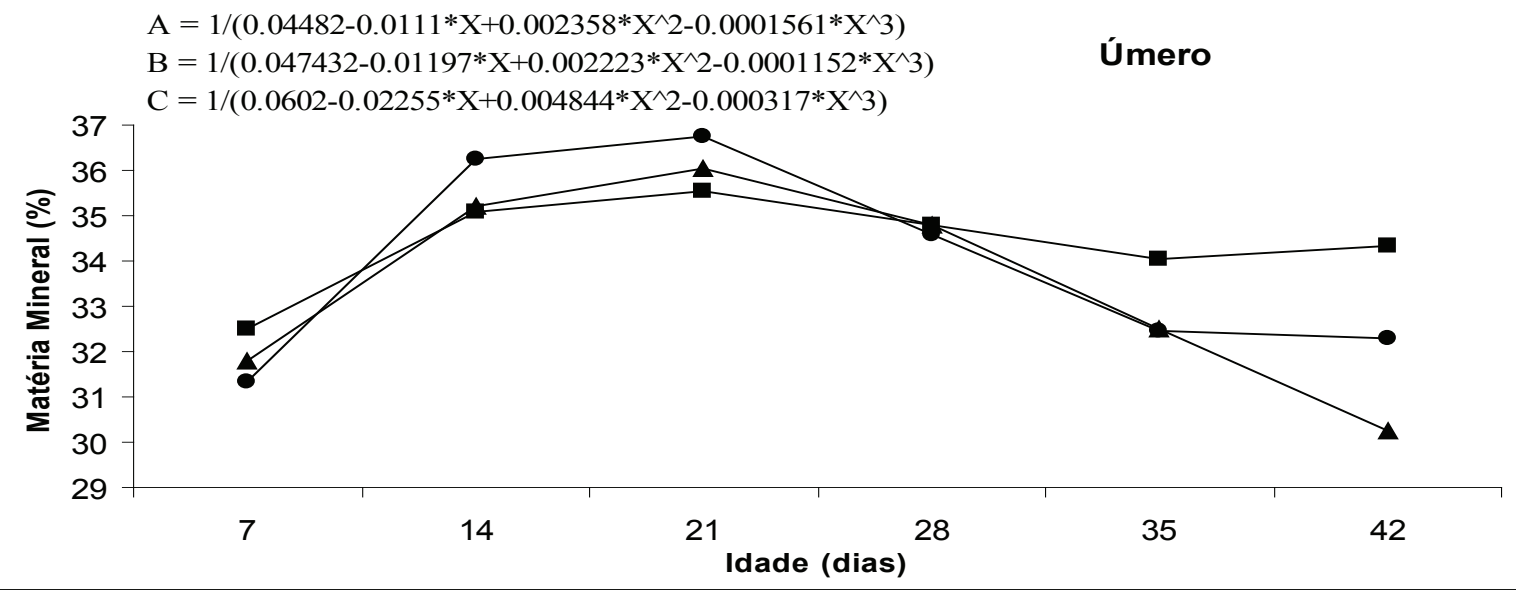

Isa Label x 10 e 16 aves/m2 (A) $\longrightarrow$ Ross x 10 e 16 aves/m2 (B) $\bullet-$ Hybro x 10 e 16 aves/m2 (C)

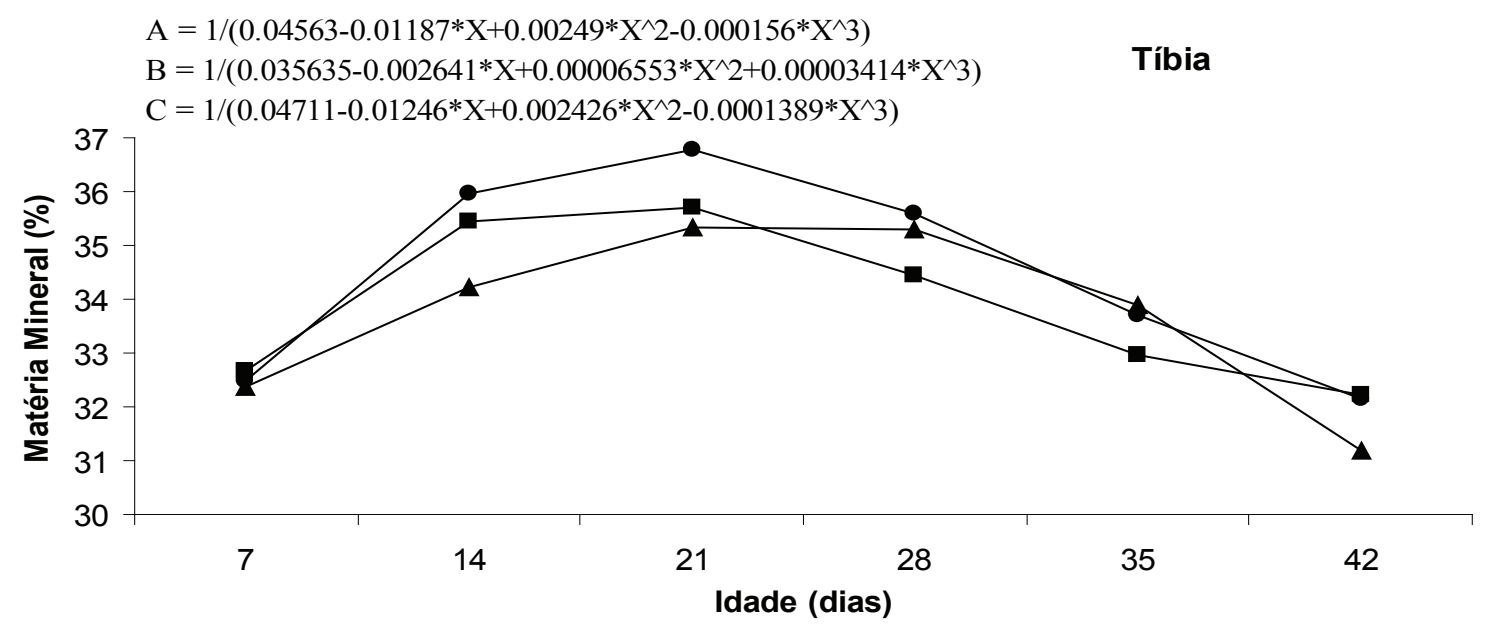

- Isa Label x 10 e 16 aves/m2 (A) \-Ross x 10 e 16 aves/m2 (B) $\bullet$ Hybro x 10 e 16 aves/m2 (C)

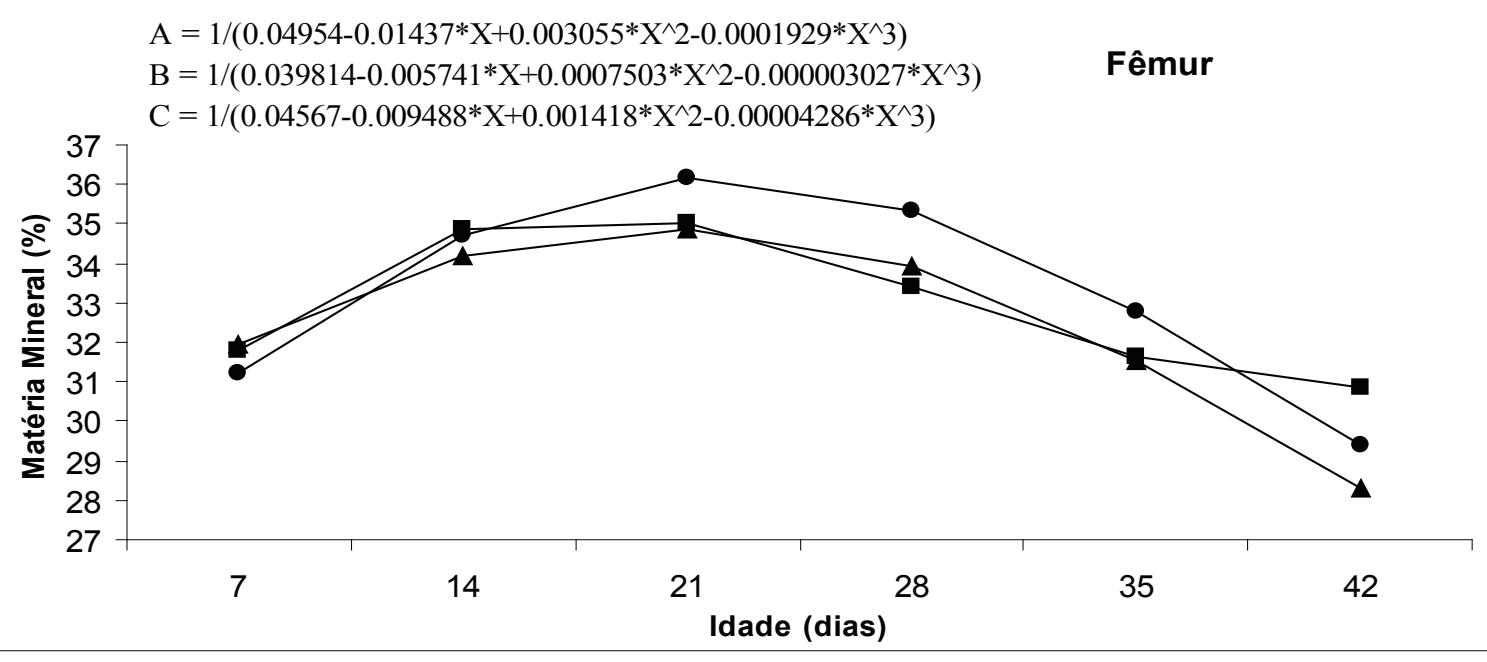

Isa Label x 10 e 16 aves/m2 (A) $\neg$ Ross x 10 e 16 aves/m2 (B) $\bullet-$ Hybro x 10 e 16 aves/m2 (C)

Fonte: Elaboração dos autores. 


\section{Conclusões}

Diferentes grupos genéticos criados em diferentes densidades populacionais não apresentaram diferenças nas características (resistência à quebra, densidade e cinzas) de desenvolvimento dos ossos longos (úmero, tíbia e fêmur), sendo que o maior desenvolvimento ocorreu nas três primeiras semanas de idade das aves.

\section{Referências}

ARAÚJO, C. S. S.; BARALDI-ARTONI, S. M.; ARAÚJO, L. F.; JUNQUEIRA, O. M.; LOUZADA, M. J. Q.; OLIVEIRA, D. Densidade óssea de frangos de corte alimentados com diferentes níveis de aminoácidos e cálcio durante a fase final de criação. Acta Sci. Animal Science, Maringá, v. 28, n. 2, p. 203-208, apr./june, 2006.

BARREIRO, F. R.; SAGULA, A. L.; JUNQUEIRA, O. M.; PEREIRA, G. T.; BARALDI-ARTONI, S. M. . Densitometric and biochemical values of broiler tibias at different ages. Poultry Science, Champaign, v. 88, n. 12, p. 2644-2648, 2009.

BIZERAY, D.; ESTEVEZ, I.; LETERRIER, C.; FAURE, J. M. Influence of increased environmental complexity on leg condition, performance and level of fearfulness in broilers. Poultry Science, Champaign, v. 81, p. 767-773, 2002.

BRUNO, L. D. G.; FURLAN, R. L.; MALHEIROS, E. B.; MACARI, M. Influence of early quantitative food restriction on long bone growth at different environmental temperatures in broiler chickens. British Poultry Science, Edinburgh, v. 41, n. 4, p. 389-394, 2000.

BRUNO, L. D. G.; LUQUETTI, B. C.; FURLAN, R. L.; MACARI, M. Influence of early quantitative feed restriction and environmental temperature on long bone development of broiler chickens. Journal of Thermal Biology, New York, v. 32, n. 6, p. 349-354, 2007.

COOK, M. E. Skeletal deformities and their cause: introduction. Poultry Science, Honduras, v. 79, p. 982984, 2000.

EDWARDS JUNIOR, H. M. Nutrition and skeletal problems in poultry. Poultry Science, Honduras, v. 79, p. 1018-1023, 2000.
HALL, L. E.; SHIRLEY, R. B.; BAKALLI, R. I.; AGGREY, S. E.; PESTI, G. M.; EDWARDS JUNIOR, H. M. Power of two methods for estimation of bone ash broilers. Poultry Science, Honduras, v. 82, p. 414-418, 2003.

KNOTT, L.; BAILEY, A. J. Collagen cross-link in mineralizing tissues: a review of their chemistry, function and clinical relevance. Journal Bone Mineral Research, Tokyo, v. 22, n. 3, p. 191-197, 1998.

LOUZADA, M. J. Q.; PELÁ, C. A.; BELANGERO, W. D.; PINTO, R. S. Avaliações de densidade óssea em imagens radiográficas: estudo em peças ósseas de cães. RBE - Caderno de Engenharia Biomédica, v. 14, n. 1, p. 47-64, 1998.

NELDER, J. A.; WEDDERBURN, W. M. Generalized linear models. Journal Royal Statistic Society, v. 135, n. 3, p. 370-384, 1972.

NATIONAL RESEARCH COUNCIL - NRC. Nutrients requeriments of poultry. Washington: National Academy Science, 1994. $114 \mathrm{p}$.

ONYANGO, E. M.; HESTER, P. Y.; STROSHINE, R.; ADEOLA, O. Bone densitometry as an indicator of percentage tibia ash in broiler chicks fed varying dietary calcium and phosphorus levels. Poultry Science, Honduras, v. 82, p. 1787-1791, 2003.

PRAUL, C. A.; FORD, B. C.; GAY, C. V.; PINES, M.; LEACH, R. M. Gene expression and tibial dischondroplasia. Poultry Science, Honduras, v. 79, p. 1009-1013, 2000.

RATH, N. C.; BALONG, J. M.; HUFF, W. E. Comparative differences in the composition and biochemical properties of tibiae of seven-an seventy-two-week-old male and female broiler breeder chickens. Poultry Science, Honduras, v. 78, p. 1232-1239, 1999.

ROSTAGNO, H. S.; ALBINO, L. F. T.; DONZELE, J. L.; GOMES, P. C.; FERREIRA, A. S.; OLIVEIRA, R. F.; LOPES, D. C. Tabelas brasileiras para aves e suinos. Composição de alimentos e exigências nutricionais. Viçosa: UFV, 2000. 141 p.

SORENSEN, P.; SU, G.; KESTIN, S. C. Effects of age and stocking density on leg weakeness in broiler chickens. Poultry Science, Honduras, v. 79, p. 864-870, 2000 . 
